\title{
Optics education for K-12
}

James Bilbro, Janice Gaines Walker

James W. Bilbro, Janice M. Gaines Walker, "Optics education for K-12," Proc. SPIE 3831, Sixth International Conference on Education and Training in Optics and Photonics, (16 June 2000); doi: 10.1117/12.388721

Event: Education and Training in Optics and Photonics (ETOP'99), 1999, Cancun, Mexico 


\title{
Optics education for K-12
}

\author{
James W. Bilbro ${ }^{a}$ and Janice Gaines Walker ${ }^{b}$ \\ ${ }^{a}$ Chair, SPIE Education Committee and Special Assistant for Optics, MS DA01 \\ NASA, George C. Marshall Space Flight Center, AL 35812 USA \\ birector, SPIE Membership \& Education Services, \\ SPIE - The International Society for Optical Engineering P.O. Box 10, \\ Bellingham, Washington 98227-0010 USA
}

\begin{abstract}
The SPIE Education Committee has developed an outreach program aimed at enhancing the dissemination of information about optics to children in kindergarten through the $12^{\text {th }}$ grade $(\mathrm{K}-12)$. The main impetus behind the program was that more practicing optical scientists and engineers would be willing to give lectures and demonstrations aimed at inspiring the next generation about optics if material could be made easily available. Consequently, three instructional "outreach kits" were assembled for use in teaching optics to kids in exciting and fun ways. These kits were beta-tested over the last two years at six different U.S. regional sites: Huntsville, Alabama; San Diego, California; Storrs, Connecticut; Orlando, Florida; and Terre Haute, Indiana. Each "outreach kit" contained: 1) a workbook on Optical Demonstrations on the Overhead Projector; 2) a Science and Math Experience Mamual: Light, Color and Their Uses; 3) The Optics Discovery Classroom Kit; 4) a slide show; and 5) a video on careers in optics. The beta tests were aimed at evaluating the practical ways of utilizing the kits, developing easy-to-follow instructions for guiding others in their use and providing suggestions on modifications, additions, and deletions to the kits. This paper discusses this outreach program and provides details relative to the kit's composition and future plans.
\end{abstract}

\section{INTRODUCTION}

There is an ever-increasing problem within the U.S in obtaining employees with the necessary skills in the areas of mathematics, science and engineering. This is due to an increased demand for hi-tech jobs coupled with a lack of students entering these areas of study. In optical science and engineering, the problem is particularly acute in that there are very few schools of higher education that have this as a dedicated area of concentration. Consequently the resource pool for hiring is already small to start with - many individuals are entering the field with degrees in physics, electrical engineering, mechanical engineering, etc and consequently requiring further training on the job. The problem will become exacerbated in coming years as the optics industry explodes in response to the demand for increasing bandwidth and storage resulting from the public's thirst for information. Additionally, the absence of women and minority students in the current workforce pipeline is particularly troubling in that they represent the dominant source for the future workforce. This is in part due to the fact that as young children, cultural expectations dictate that the areas of mathematics, science and engineering are unattainable areas of endeavor. Consequently, people lose interest at a young age and by the time they are ready to make career determining choices of study, these areas are no longer options.

The answer to this problem - to a substantial part lies with improving the exposure of our children to optics! Children have a natural curiosity that - if properly nourished - will blossom into careers that not only yield lifelong personal enjoyment, but that also provide products and technologies benefiting the whole of mankind. By middle school (grades 6-9) the majority of children perceive math as grueling drudgery and science as boring. It is at this point in the education system that young girls in particular are lost to the scientific areas, such study being deemed "not cool" by peers and "inappropriate" by adults. With respect to minorities, the educational culture has long dictated that these technical areas are "too difficult" to be realistically considered as attainable careers. The problem has many facets, children's socio-economic background, parental interest, teacher training, curriculum content etc. However, in spite of the many difficult aspects of the problem there is one area that can be realistically drawn upon to make a difference - mentoring! Children's interest in scientific and technical areas can be stimulated by contact with individuals that have successfully pursued careers in these areas. Increased number and duration of contacts with mentors will increase children's interest in scientific and technical areas and consequently more children will pursue educational paths that will culminate in careers in these areas. 
In order to help alleviate future work force problems, the SPIE has undertake a series of activities which are aimed at stimulating children's interest in pursuing careers in optical science and engineering. These activities include the production and distribution of a video on careers in optics and the assembly and distribution of a K-12 outreach optics kit containing materials for use in demonstrating the principals of optical science and engineering.

\section{OPTICS OUTREACH KIT}

The underlying basis for the decision to assemble theK-12 Outreach Kit was two-fold. First, there are many practicing optical scientists and engineers ready and willing to give talks and demonstrations to students of all ages. Second, the major barrier to this process is ready access to demonstration material. (It has been the all too frequent experience of one of the authors (Bilbro) to readily agree to give a talk at a local school only to panic at the last minute trying to find something that would interest the particular age group being addressed and to swear never to agree to give a talk again.)

The kit contains the following material.

1. A series of slides on lasers and other material provided by M.J. Soileau, and the University of Central Florida's Center for Research in Education in Optics and Lasers (CREOL).

2. The Optical Society of America's Optics Discovery Classroom Kit.

3. The NASA Marshall Space Flight Center's "Science and Math Experience Manual: Light, Color and Their Uses."

4. A Workbook and notes on "Optical Demonstrations with the Overhead Projector" by Doug Goodman, Polaroid Corporation.

5. The video entitled "Career Encounters: Optics \& Photonics," produced by Davis Gray, Inc.

\subsection{CREOL Slides}

The first set of materials to be included in the kit was provided by M.J. Soileau and the staff of the University of Central Florida's Center for Research in Education, Optics and Lasers (CREOL). M.J. assembled a series of slides and other material in the course of giving many presentations to local schools and other groups in the Orlando area. The primary focus of this material is on the laser, its operation and many applications. One example of the more than 50 slides is shown in figure 1.

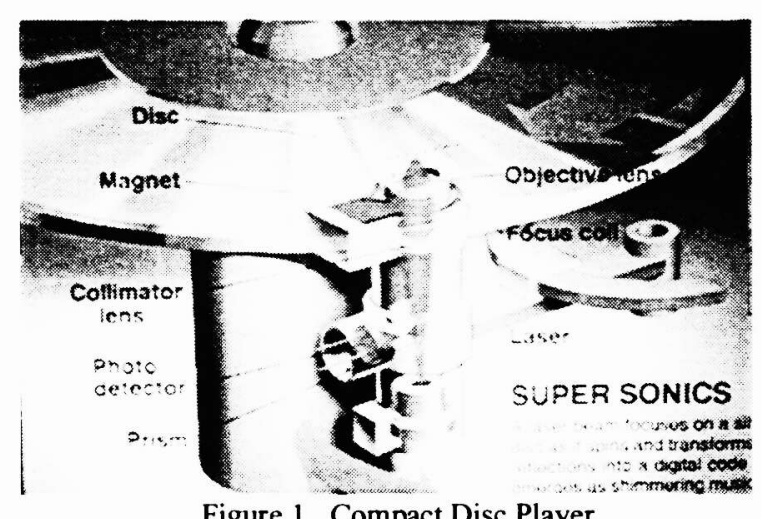

\subsection{OSA's Optics Discovery Classroom Kit}

In the late 1980's, the Membership \& Education Services Council of the Optical Society of America decided to put together a kit that would stimulate the interest of children in the area of optics. The kit was the brainchild of Professor Donald O'Shea of the Georgia Institute of Technology. Don designed the kit and the first kits were produced and marketed by Paul Forman. Since 1990 the OSA Optics Discovery Kit and its companion the OSA Optics Discovery Classroom Kit have been produced and distributed by the Edmund Scientific Company. The Discovery Kit is oriented toward the individual student and contains descriptive material on experiments as well as components for the experiments. The Classroom Kit consists of 16 copies of the basic kit plus a reproducible student guide and a teacher's manual. The basic kit contains the following materials: 11 experiment cards, 1 meter of optical fiber, 1 diffraction grating, 1 optical illusion slide, 1 Fresnel lens, 1 flexible mirror, 3 plastic lenses, 1 hologram, 2 polarizers and 4 color filters. 
Additional material is necessary to complete the kit, including index cards, light bulbs, plastic wrap, rulers, clothespins, spoons and sugar and salt. This material is readily available around most households, and should be obtainable without too much difficulty. an example of an experiment card from the kit is shown in figure 2.

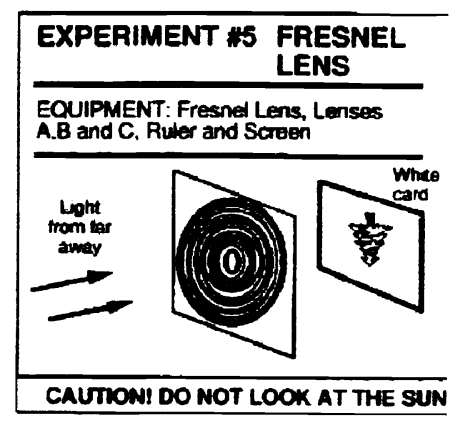

Some Things To Think About

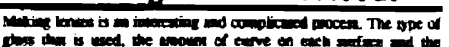

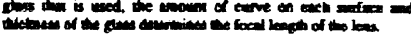

How 18 This Usoful?

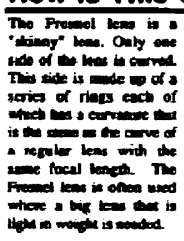

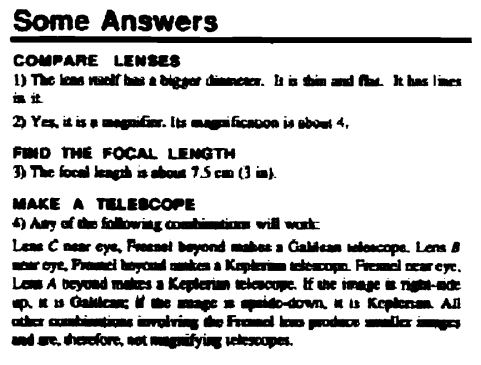

Things To Do

\section{כOMPARE LENEES}

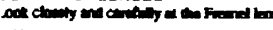

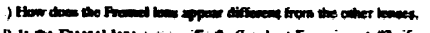

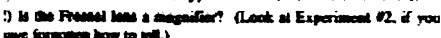

NO NHE FOCNL LENGTH

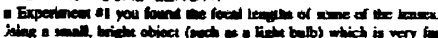

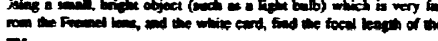

$\rightarrow$ ins.

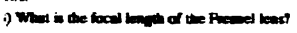

LAKE a TELEscore

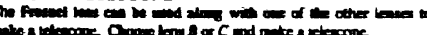

Figure 2. Experiment card from the OSA Discovery Kit on the Fresnel lens.

\subsection{NASA MSFC's Science and Math Experience Manual: Light, Color and Their Uses}

In 1991, the National Aeronautics and Space Administration's George C. Marshall Space Flight Center initiated a program aimed at providing local teachers and students with access to scientists and engineers. This program, known as project LASER (Learning About Science, Engineering and Research) set up a laboratory for teacher and student access and produced a number of workbooks aimed at providing information on selected topics. One of the workbooks produced dealt with light. This workbook contains over twenty experiments that can be built by students using very inexpensive readily available materials. It also contains resource information for teachers to go beyond that provided in the workbook. An example of one of the experiments is shown in Figure 3.

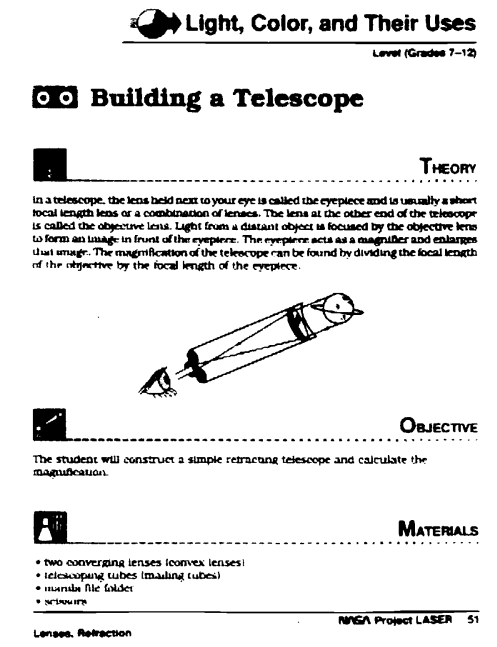

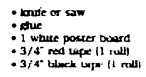
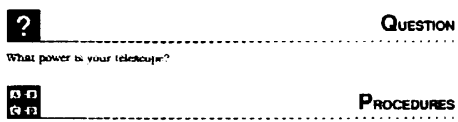

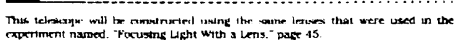

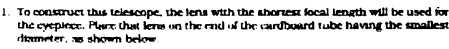

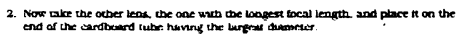

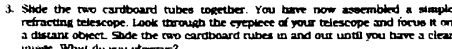
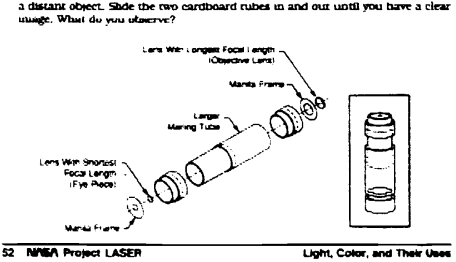

Figure 3. Experiment from "Light, Color and their Uses " on building a simple telescope 


\subsection{Optical Demonstrations with the Overhead Projector}

Doug Goodman of the Polaroid Corporation has been giving demonstrations of optical phenomena using overhead projectors for almost 10 years now. The extremely entertaining nature of Doug's presentations, combined with the tremendous amount of information provided (which could be easily tailored to various age groups and education levels) made this workbook a natural choice for inclusion in the kit.

The following figures shows two of the more than 150 demonstrations described in Doug's workbook. The workbook as a whole is a fascinating collection of ideas on demonstrating phenomena ranging from the very simple to the very complex, using simple, inexpensive materials. The beauty of this workbook is that it can be used at all levels, from demonstrating "gee whiz" colorful experiments that catch the eye of a kindergartner to demonstrating sophisticated Moire' patterns as they relate to interferometry for the graduate student. It should be noted that kindergartners also enjoy Moire' patterns as well - the demonstration doesn't change, but the explanation for the graduate students is probably a little more in depth.

\section{INSIDE AN OVERHEAD PROJECTOR}

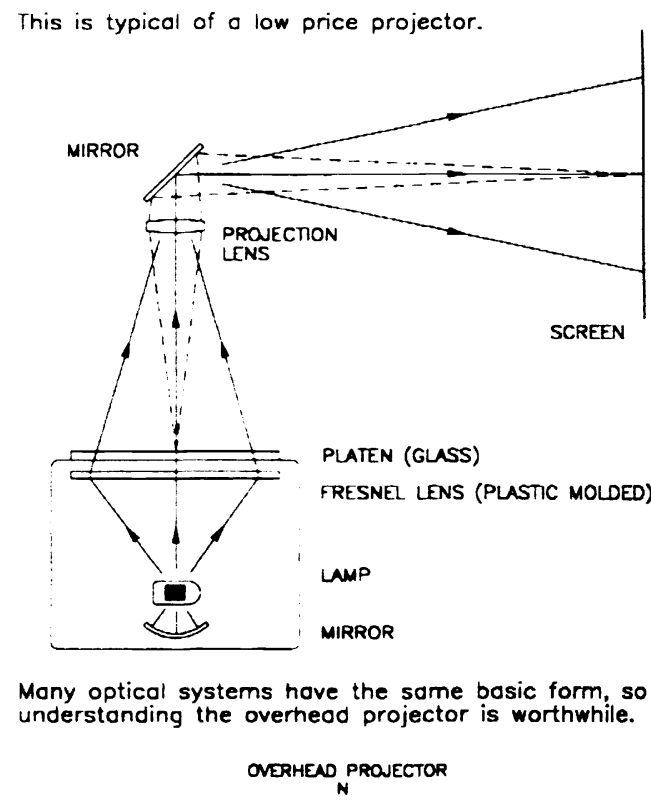

Figure 4. The Overhead Projector

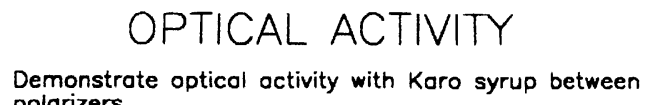
polarizers.

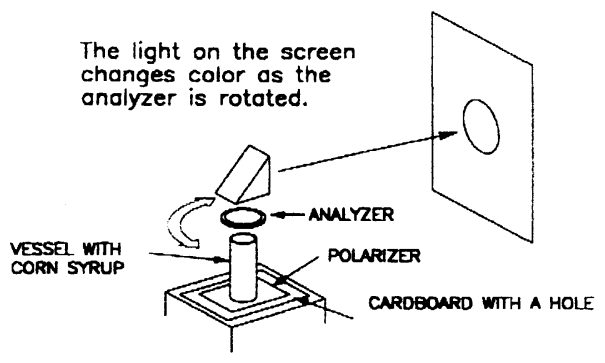

Set the polarizer and anlyzer for extinction.

Insert the vessel with corn syrup and colors appear.

Turn the analyzer and observe the color changes.

Rotate the syrup vessel and nothing happens.

Try different depths of syrup.

Try color filters.

Bubbles in the syrup detract. Pour the syrup in advance to let them deport.

The vessel should have a flat bottom. See the section on Rayleigh scattering. Make sure the bottom is not birefringent.

$$
\text { POLARIZATION }
$$

Figure 5. Optical Activity

\subsection{Career Video}

In the spring of 1995, the SPIE, the OSA and the Center for Occupational Research and Development (CORD) signed agreements to co-sponsor a video aimed at promoting careers in optics and photonics. It was produced by Davis Gray, Inc., as part of their Career Encounters series. The content was developed through input from SPIE, OSA and CORD members and staff, and through interviews and information conducted and collected by Davis Gray. The video was finalized in May 1996 and in April 1997, it was granted the Award for Excellence and Innovation in Career Education by the American Association for Career Education. The video is 28 minutes in length and covers a wide variety of careers ranging from traditional optical fabrication and testing, through space astronomical observatory development and operation, laser development and application and various aspects and applications of photonics. A frame from the video is shown in

Figure 6. 


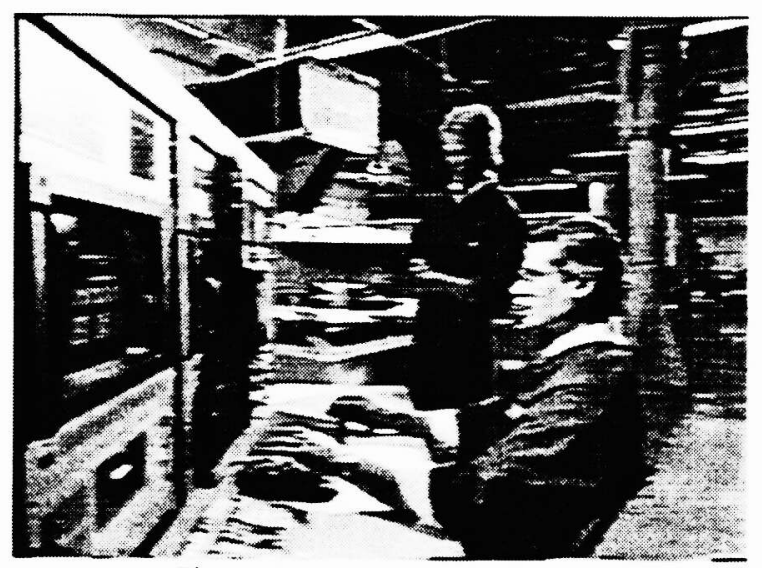

Figure 6. Career Encounters video

\section{Beta Testing}

In order to judge the efficacy of the proposed project, as well as to obtain suggestions on use, modifications, additions, and deletions, it was decided to assemble three kits and to distribute them to different locations within the U.S. The first year, the kits were distributed to: The Rose-Hulman Institute of Technology, Terre Haute, IN, with Dr. Brij Khorana as the point of contact; The University of Alabama in Huntsville, Huntsville, AL with Dr. John Dimmock as the point of contact; and The University of Central Florida, Orlando, FL with Dr. M.J. Soileau as the point of contact. In the second year of testing, two additional kits were assembled and provided to Dr. Chandra Roychoudhuri at the University of Connecticut, Storrs, CT, and to Mr. Joe Lones of the San Diego Chapter of the OSA, San Diego, CA. The kit at Rose-Hulman was transferred to Dr. Rick Shoemaker at the University of Arizona, Tucson, AZ, . As a result of the beta tests, a number of changes are being planned for later incorporation into the kits. Doug Goodman is revising his workbook and notes on "Optical Demonstrations with the Overhead Projector," and a video is currently in production supporting this workbook. An example taken from the video is shown in figure 7. Additionally, a video is now in planning aimed at teaching teachers how to use the OSA Optics Discovery Kit and the video accompanying the NASA workbook is being considered for release. A frame from this video is shown in figure 8. A kit accompanying the NASA workbook is also being considered.

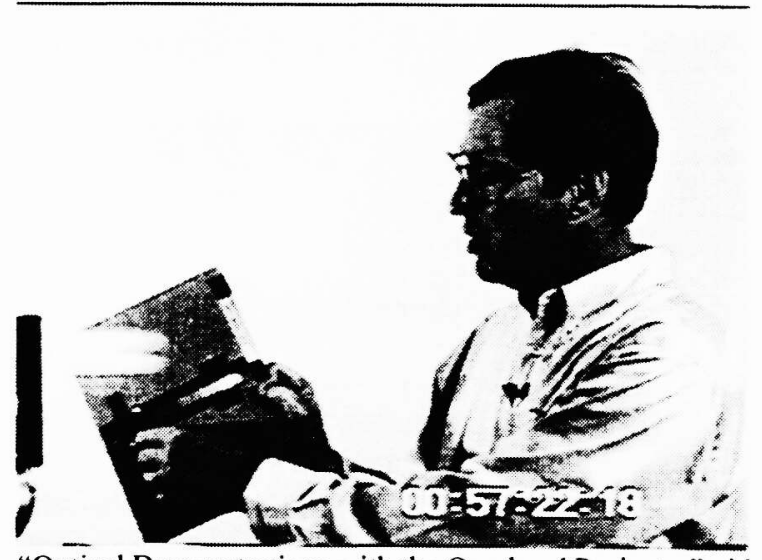

Figure 7. "Optical Demonstrations with the Overhead Projector" video

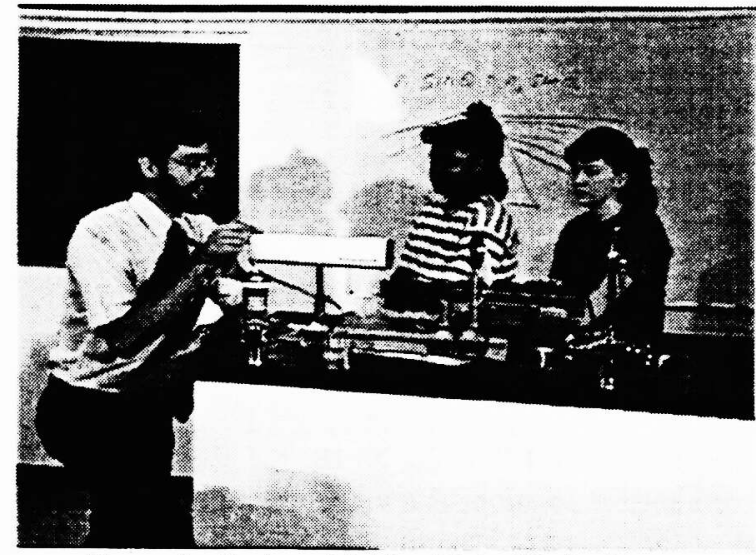

Figure 9. Optics - Making Light Work video

\section{Summary}

The results from the Beta testing has shown the K-12 Optics Outreach Kit to be very successful in stimulating interest among students and facilitating presentations and demonstrations by practicing optical scientists and engineers. Demonstrations and/ or presentations have been made in a number of different venues beyond the school setting and to date requests have been made for 15 additional kits. Midway through the Beta testing, the OSA's Membership and Education Services Council voted to participate and the program is now moving forward with joint SPIE/OSA participation. As a result of the success of this program, the SPIE's Education Committee has decided to create 30 new kits for distribution in the coming year and to consider providing additional kits as needed in the future. 


\section{Acknowledgements}

The authors would like to express their appreciation for the many individuals that provided information for this paper, including Kari Amundson of the OSA, Pascale Barnett of the SPIE, Don Gregory, University of Alabama in Huntsville, and Michael Leavenworth, Curie Elementary School, San Diego, CA. Special thanks are also due to the Points of Contact during the beta testing: John Dimmock, Brij Khorana, Joe Lones, Chandra Roychoudhuri, Rick Shoemaker and M.J. Soileau. 